\title{
Examining the Awareness and Attitude of Specific Group on Epilepsy in Gaza Strip, Palestine
}

\author{
Abdelnaser Omran ${ }^{1}$, Fulla Sharaf ${ }^{2}$ \\ ${ }^{1}$ School of Economics, Finance and Banking, College of Business, Universiti Utara Malaysia, Sintok, Malaysia \\ ${ }^{2}$ Head of Primary Health Care Information Department, Palestinian Health Information Centre, Ministry of Health, Gaza Strip, Palestine
}

Email address:

naser_elamroni@yahoo.co.uk (A. Omran)

\section{To cite this article:}

Abdelnaser Omran, Fulla Sharaf. Examining the Awareness and Attitude of Specific Group on Epilepsy in Gaza Strip, Palestine. International Journal of Neurologic Physical Therapy. Vol. 3, No. 3, 2017, pp. 21-24. doi: 10.11648/j.ijnpt.20170303.12

Received: April 24, 2017; Accepted: May 15, 2017; Published: June 5, 2017

\begin{abstract}
Epilepsy is one of the most common serious and chronic neurological disorder worldwide. This study aimed to examine the awareness, knowledge, and attitude of people about epilepsy Gaza strip. With One hundred and fifteen questionnaires were distributed to the public, only ninety-seven questionnaires were completed and returned, giving a response rate of $84.3 \%$. This paper concludes that the awareness, attitude and knowledge of the public towards epilepsy are positive; and all of the participants positively believed that epilepsy is not a contagious disease and $96.9 \%$ of the participants indicated that epilepsy is a psychological disease. However, there are some misconceptions about epilepsy, whereby some participants (68\%) believe that believed that people with epilepsy should not participate in social activities. Several recommendations were made by the respondents for those suffer from epilepsy. One of these recommendations is that any persons with epilepsy, he or she is necessary to be prevented from participating in the sportive activities.
\end{abstract}

Keywords: Epilepsy, Awareness, Attitude, Professional, Students, Gaza Strip

\section{Introduction}

The term 'epilepsy' refers to a group of central nervous system disorders manifesting in seizures [1], and is the umbrella diagnosis given to people who have recurrent i.e., two or more [2] (Banerjee et al., 2009), unprovoked seizures [3]. Originally, epilepsy comes from a Greek word meaning "to hold or seize", and people who have epilepsy have seizures. Fisher [4] \& Elaine [5] defined it as a brain disorder characterised by an enduring predisposition to generate epileptic seizures and by the neurobiologic, cognitive, psychological, and social consequences of the condition. Epilepsy is a disease or a condition, characterized by the occurrence of sporadic electrical storms in the brain called seizures. However, the commonly used definition of epilepsy according to the International League Against Epilepsy (ILAE), is the occurrence of two unprovoked seizures, more than 24 hours apart [4]. Epilepsy has been present during the entire development of humankind from prehistory to the present time [17]. There are over 50 million sufferers in the world today, $85 \%$ of whom live in developing countries. Epilepsy is the most common neurological disorder of childhood [18]. Not only the disease itself, but also the medications used in its treatment may lead to certain cognitive, psychosocial, and behavioral problems. The perception of epilepsy in societies may differ depending on the level of education, awareness and cultural beliefs of the society. People might associate epilepsy with supernatural causes or contamination; however, as the level of education and income increase, attitude towards epilepsy improves in the society [6, 7]. For instance, the percentages of people who have either read or heard about epilepsy were found to be $97 \%$ in Denmark [8], $95 \%$ in USA [9], and $73 \%$ in Italy [10]. In studies carried out in Brazil and Thailand, the rates of awareness about epilepsy among school teachers were found to be $98-100 \%$ and $57.8 \%$, respectively $[11,12]$. The main of this study was to examine the awareness, knowledge, and attitudes of the public in Gaza Strip about epilepsy. Epilepsy is a symptom of a variety of underlying etiological causes, rather than a specific disease [13]. The most common etiologic factors of epilepsy that can predispose a person to epilepsy are head traumas, neoplasms, degenerative diseases, infections, metabolic diseases, ischemia and hemorrhages [13]. In a study conducted on epilepsy management in Africa by Lugthart [15] recommended to put an emphasis on 
educating the public and teachers as well, in order to minimize stigma towards epilepsy and to add value to the quality of life for the people living with epilepsy. Another study conducted in Germany strongly recommended that education about epilepsy needs to be given to the teachers and the public at large, because they have discovered that the quality of life of students with epilepsy may seriously be affected by the attitudes of their families and teachers, if they are unaware of or uneducated about their condition [16]. A positive attitude and good practices towards epilepsy was found to have a positive influence and can contribute to the successful school adjustment in children with epilepsy. Similarly, the teachers ${ }^{\text {ee }}$ attitudes towards epilepsy were found to have predicted their knowledge about epilepsy [19].

\section{Methods and Materials}

The data was collected using the questionnaire survey method. In this study the target population was the professional in medical filed in Gaza Strip, Palestine. The data collection was done between $5^{\text {th }}$ September until $25^{\text {th }}$ October 2016. This study was a cross-sectional survey involving the administration of 115 questionnaires to specific people who are working in the health sector such as doctors, nurses, technician and also final year medical students who are attending their practical courses at hospital before final graduation from faculty of medical in Gaza strip, of which 97 were returned and analyzed, giving a response rate of $84.4 \%$. The questionnaire was adopted from Omran et al. [16] who conducted a study on awareness and attitude of University Students and Staff on Epilepsy in Malaysia and issues of integrating people with Epilepsy into society and the labour market in Germany and also from Bekiroğlu [20] who had conducted a study on awareness and attitude of teachers on epilepsy in Istanbul. The questionnaire's items were covered several sections such (a) awareness and knowledge; (b) attitudes; (c) management of epilepsy; (d) employment, driving; and, (e) social activities. The data collected was processed by using Statistical Package for Social Science (SPSS) program for Windows (Version 22.0) and a frequency test was used.

\section{Results of the Survey}

The results section is divided into sub-sections. All is concerning the survey which carried out in the abovementioned area of the study.

\subsection{Respondents' Background}

Table 1 shows the characteristic of the 97 respondents involved in this study. The survey shows that the gender status of the respondents has almost an equal number of the respondents between the two genders where $49(50.5 \%)$ of the respondents in this study were males and 48 (49.5\%) were females. The respondents were almost consistently distributed in all age groups, with the highest, namely $29.9 \%$ (29) falling in the age group of $31-35$ and the lowest, namely $9.3 \%$ (9) falling in the age group of $26-3041-45$ years old, and 50 years old and above. Sixteen (16.5\%) of the respondents were in the age group of 46-50 years old. The marital status of the respondents was mostly come from $(87.6 \%)$. The educational qualifications of the respondents were also surveyed, whereby the majority of $50(50.5 \%)$ of the respondents were holders of a Bachelor's degree in education, while thirty-eight (39.1\%) had Master's degree. The job description of the respondents was mostly come from nurses $(39.2 \%)$, psychologist (19.6\%), and followed by medical doctor $(14.4 \%)$.

Table 1. Respondents Background in this study.

\begin{tabular}{|c|c|c|}
\hline Items & Frequency & $\%$ \\
\hline \multicolumn{3}{|l|}{ Gender } \\
\hline Male & 49 & $50.5 \%$ \\
\hline Female & 48 & $49.5 \%$ \\
\hline \multicolumn{3}{|l|}{ Residential area } \\
\hline North Gaza & 14 & $14.4 \%$ \\
\hline Gaza & 34 & $35.1 \%$ \\
\hline Middle zone & 30 & $30.9 \%$ \\
\hline Khan Younes & 10 & $10.3 \%$ \\
\hline Rafah & 9 & $9.3 \%$ \\
\hline \multicolumn{3}{|l|}{ Age categories } \\
\hline $18-25$ years' old & 11 & $11.3 \%$ \\
\hline $26-30$ years' old & 9 & $9.3 \%$ \\
\hline $31-35$ years' old & 29 & $29.9 \%$ \\
\hline $36-40$ years' old & 14 & $14.4 \%$ \\
\hline $41-45$ years' old & 9 & $9.3 \%$ \\
\hline $46-50$ years' old & 16 & $16.5 \%$ \\
\hline 50 years old and above & 9 & $9.3 \%$ \\
\hline \multicolumn{3}{|l|}{ Marital Status } \\
\hline Married & 12 & $12.3 \%$ \\
\hline Single & 85 & $87.6 \%$ \\
\hline \multicolumn{3}{|l|}{ Educational level } \\
\hline Diploma degree & 9 & $9.3 \%$ \\
\hline Bachelor degree & 50 & $51.5 \%$ \\
\hline Master degree & 38 & $39.1 \%$ \\
\hline $\mathrm{PhD}$ degree & - & - \\
\hline \multicolumn{3}{|l|}{ Job description } \\
\hline Medical doctor & 14 & $14.4 \%$ \\
\hline Nurse & 38 & $39.2 \%$ \\
\hline Pharmacist & 10 & $10.3 \%$ \\
\hline Psychologist & 19 & $19.6 \%$ \\
\hline Social worker & 10 & $10.3 \%$ \\
\hline Student & 6 & $6.2 \%$ \\
\hline
\end{tabular}

\subsection{Examining the Public Knowledge, Attitudes, Awareness} on Epilepsy

The results section is divided into sub-sections. All is concerning the survey which carried out in the abovementioned area of the study.

\subsubsection{Knowledge and Awareness}

All of the participants $(100 \%)$ had either read or heard about epilepsy. Although, the participants were having knowledge and awareness on this disease. Only 55.7\% knew someone suffering from such disease and the majority of the 
respondents $(80.4 \%)$ had seen someone having a seizure. However, $100 \%$ of the participants positively believed that epilepsy is not a contagious disease. Concerning the question whether epilepsy is a psychological disease or not. As results, it was found that $96.9 \%$ of the participants indicated that epilepsy is a psychological disease (Table 2). In relation to the question "whether if epilepsy a disease that can be treated or not. The majority of the participants $(96.9 \%)$ responded in the affirmative that it can be treated.

Table 2. Presents the Respondents' Knowledge and Awareness.

\begin{tabular}{ll}
\hline Items & \% \\
\hline $\begin{array}{l}\text { Have you ever read / heard something about epilepsy? } \\
\text { Yes }\end{array}$ & $100 \%$ \\
No & - \\
Do you know a person with epilepsy? & \\
Yes & $45 \%$ \\
No & $55 \%$ \\
Have you ever seen someone having a seizure? & \\
Yes & $81 \%$ \\
No & $19 \%$ \\
Is epilepsy a contagious disease? & \\
Yes & - \\
No & $100 \%$ \\
Is epilepsy a psychological disease? & \\
Yes & $3 \%$ \\
No & $97 \%$ \\
\hline
\end{tabular}

\subsubsection{Attitudes Towards People with Epilepsy}

When queried on if it is appropriate for a person with epilepsy to get married, most of the respondents (99\%) of the respondents agreed. They have also agreed that patients with epilepsy can have children (99\%), but surprisingly large proportion of them were hesitant about marrying a person with epilepsy themselves (98\%). These results are presented in Table 3 as shown below.

Table 3. Shows the Respondents' Knowledge and Awareness.

\begin{tabular}{lc}
\hline Items & $\%$ \\
\hline Appropriate to get married for a person with epilepsy & $99 \%$ \\
Yes & $1 \%$ \\
No & \\
Appropriate for a person with epilepsy to have a child & $99 \%$ \\
Yes & $1 \%$ \\
No & \\
Willing to marry a person with epilepsy & $2 \%$ \\
Yes & $98 \%$ \\
No & \\
Approval for your child to share activities with a friend who suffered from \\
epilepsy & $80 \%$ \\
Yes & $20 \%$ \\
No & $8 \%$ \\
Approval for your son or daughter married a person with epilepsy \\
Yes & $92 \%$ \\
No & \\
Your opinion on a person with epilepsy for living alone & $2 \%$ \\
Yes & $98 \%$ \\
No & \\
\hline
\end{tabular}

\subsubsection{Explanation on Managing Epilepsy}

In this section, the study was focused on knowing the participants' awareness concerning epileptic seizures and their management after conducting the survey. As results, it found that $98 \%$ of the respondents believed that every person with epileptic seizure has to use an antiepileptic drug. Furthermore, $97 \%$ of the participants knew that some people with epilepsy need life-long drug treatment, 97.9\% stated that smelling eau de cologne or onion can help to end an epileptic seizure. Relating to the question "do you think it is sensible to hold the arms and legs during a seizure with convulsion", $99 \%$ of the participants stated that it is reasonable to do so.

\subsubsection{Knowledge on Practicing Some Activities}

In this section, the study was focused on the participants' knowledge by asking few questions related to some activities such employment, driving and social activities to whether a person with epilepsy will be able to practice them or not. As results, it can be found that the vast majority of the participants thought that people with epilepsy could be successful in professions such as executive secretary, physician, etc $(96.9 \%)$ and acknowledged that students with epilepsy could be successful in normal classes (99\%). Questions concerning the eligibility of the people with epilepsy to drive were answered not negatively where $67 \%$ of the respondents agreeing to this point. In addition, the majority $(69 \%)$ of the respondents believed that people with epilepsy should participate in social activities. As per sport activities, it the survey shows that all the respondents (100\%) who participated in this study thought that it was necessary for persons with epilepsy to be prevented from participating in the sportive activities.

\section{Conclusion}

This study aimed to examine the awareness, knowledge, and attitude of people about epilepsy in Gaza strip, Palestine. It can be concluded that all of the participants were knowledgeable enough about epilepsy and they had either read or heard about epilepsy from different sources. Also, the participants had positively reported that epilepsy is not a contagious disease. Despite the respondents being supportive for patients with epilepsy to get married and have children, $98 \%$ of them stated that they would not be welcoming the idea of getting married from a person suffers from epilepsy. In addition, this study revealed that the majority of the participants had reported that people with epilepsy are allowed to participate in activities such social activities, sport activities and etc. The study recommended that even though the participants were professional in medical field and have sufficient knowledge and information on epilepsy but there are still more efforts needed to educate students prior to their graduation and practices their medical jobs on the meaning of epilepsy, especially about the causes, signs and symptoms of the condition, as well as the management of seizures. 


\section{Acknowledgement}

The authors would like to express their sincere thanks those who participated in this study.

\section{References}

[1] S. Baxendale, Epilepsy: An approach to case formulation. Formulation and treatment in Clinical Health Psychology. V. Nikcevic Ana, A. Kuczmierczyk, R. and M. Bruch. Hove, Routledge, 2006.

[2] P. N., Banerjee, D. F., Hauser, \& W. Allen Hauser, The descriptive epidemiology of epilepsy- A review. Epilepsy Research, 2009, 85; pp. 31 - 45.

[3] R. Guerinni, Epilepsy in children. Lancet, 2006, 367, pp. 499 524.

[4] R. S. Fisher, et al. A practical clinical definition of epilepsy, Epilepsia, 2014, 55, pp. 475-482.

[5] W. Elaine, Wyllie's Treatment of Epilepsy. Philadelphia, PA: Lippincott Williams \& Wilkins; 2011.

[6] H., Aziz, S. W., Akhtar, \& K. Z. Hasan, Epilepsy in Pakistan: stigma and psychosocial problems. A population-based epidemiologic study. Epilepisa, 1997, 38 (10), pp. 1069-1073.

[7] H. T., Rwiza, W. B. P., Matuja G. P., Kilonzo, J., Haule, P., Mbena R., Mwangombola, et al. Knowledge, attitude and practice toward epilepsy among rural Tanzanian residents. Epilepsia, 1993, 34 (6), pp. 1017-1023.

[8] R., Jensen, \& M. Dam, Public attitudes toward epilepsy in Denmark. Epilepsia, 1992, 33 (3), pp. 459-463.

[9] W. F., Caveness, \& Gallup, G. H. A survey of public attitudes toward epilepsy in 1979 with an indication of trends over the past thirty years. Epilepisa, 1980, 21, pp. 509-518.

[10] R., Canger, \& C. Cornaggia, Public attitudes toward epilepsy in Italy: results of a survey and comparison with USA and West German data. Epilepisa, 1985, 26 (3), pp. 221-226.
[11] F. G., Dantas, G. A., Cariri, G. A., Cariri, F. A. R. Ribeiro, Knowledge and attitudes towards epilepsy among primary secondary and tertiary level teachers. Arq Neuropsiquiatr, 2001, 59 (3B), pp. 712-716.

[12] P., Kankirawatana, Epilepsy awareness among school teachers in Thailand. Epilepisa, 1999, 40 (4), pp. 497-501.

[13] J. Jr., Engel, \& T. A. Pedley, Introduction: what is epilepsy? In: Engel, J. Jr \& Pedley, T. A. (eds) Epilepsy - A Comprehensive Textbook. Lippincott-Raven Publishers, Philadelphia, 1997, pp. 1-10.

[14] H. V., Vinters, D. L., Armstrong, T. L., Babb, C., DaumasDuport, Y., Robitaille, C. J., Bruton, \& M. A. Farrel, The neuropathology of human symptomatic epilepsy. In: Engel JJr (ed) Surgical treatment of the epilepsies, 2nd ed. Raven Press, New York, 1993, pp. 593-608.

[15] L., Lugthart, Epilepsy Management in Africa: Major Obstacles and Solution. Liverpool: African Health, 2011.

[16] A., Omran, O., Schwarz-Herion, \& S. Viehbacher, Awareness and attitude of University Students and Staff on Epilepsy in Malaysia and issues of integrating people with Epilepsy into society and the labour market in Germany, Journal of Pharmacy and Clinical Sciences, 2011, (3), pp. 13-23.

[17] P., Wolf, Sociocultural history of epilepsy. C. P. Panayiotopoulos (ed.), Atlas of Epilepsies, 2010, DOI 10.1007/978-1-84882-128-6_7.

[18] I., Mckinlay, I. Epilepsy Care: The problem from Child to Adult. Epilepsy in young people. In: Ross E, Chadwick D, Crawford R, editors. Wiley; 1987, pp. 3-12.

[19] A. L., Roux, Examining teacher knowledge and attitudes about school issues for children with epilepsy: A mixedmethod investigation, Unpublished $\mathrm{PhD}$ Thesis, University of Florida, USA, 2009,

http://ufdcimages.uflib.ufl.edu/UF/E0/02/48/59/00001/roux_a. pdf Retrieved on 15/2/2017.

[20] S. N., Bekiroğlu, R., Ozkan, C., Gürses, B., Arpaci, A. Dervent, A study on awareness and attitude of teachers on epilepsy in Istanbul. Seizure, 2004, 13 (7), pp. 517-522. 